\title{
A LAMP FOR OPERATIONS
}

\section{To the Editor, British Journal of Ophthalmology}

SIR, - Many surgeons must at some time have felt the need of a really efficient and portable operating lamp of a reasonable price. To those who have not already tried it I would strongly recommend a "Klaar" light, such as is used on a head band by laryngologists. As most people know, these are parabolic mirrors carrying a small electric lamp on a moveable arm which allows the intensity of the illumination to be altered.

A small adjustment readily makes the lamp take the bulb and battery of the ordinary torch lamp in place of that supplied, so that one need never be at a loss for a suitable dry battery.

The lamp is, of course, held by an assistant when used. I have found it such a boon that I must recommend it, as I do not know if it is in common use.

I am,

Yours, etc.,

H. KIRKPATRICK.

MADRAS.

\section{A NEW FORM OF BIFOCAL LENS}

To the Editor of The British Journal of Ophthalmology.

SiR,-The fact that a cylindrical quality is added to a ray of light passing obliquely through a spherical lens has frequently been noted, as also its application in the case of spectacles; but it is curious that it is only commented on in relation to the vertical axis. Although this is obviously of superior importance, the effect is no less applicable to the horizontal axis, and to intermediate directions.

This would seem to point to a preference for a Toric form of lens rather than one which is only corrected for the vertical direction. It also suggests the advantage of the small round form of disc in a bifocal lens, rather than one of extended lateral shape.

3, New Bond StREet,

$$
\text { I am, Sir, }
$$

Yours truly,

W. A. Dixey. 